\title{
Breakdown of lung framework and an increase in pores of Kohn as initial events of emphysema and a cause of reduction in diffusing capacity
}

This article was published in the following Dove Press journal: International Journal of COPD

16 September 2016

Number of times this article has been viewed

\begin{abstract}
Akira Yoshikawa,' Shuntaro Sato, ${ }^{2,3}$ Tomonori Tanaka,' Mikiko Hashisako, ${ }^{1,4}$ Yukio Kashima, ${ }^{5,6}$ Tomoshi Tsuchiya, ${ }^{7}$ Naoya Yamasaki, ${ }^{7}$ Takeshi Nagayasu, ${ }^{7}$ Hiroshi Yamamoto, ${ }^{2}$ Junya Fukuoka 1,6

'Nagasaki Educational and Diagnostic Center of Pathology (NEDCP), Department of Pathology, ${ }^{2}$ Clinical Research Center, Nagasaki University Hospital, Nagasaki, ${ }^{3}$ Division of Biostatistics, Kurume University School of Medicine, Fukuoka, ${ }^{4}$ Research Institute for Diseases of the Chest, Graduate School of Medical Sciences, Kyushu University, Fukuoka, ${ }^{5}$ Department of Pathology, Hyogo Prefectural Awaji Medical Center, Sumoto, ${ }^{6}$ Department of Pathology, ${ }^{7}$ Division of Surgical Oncology, Department of Translational Medical Sciences, Nagasaki University Graduate School of Biomedical Sciences, Nagasaki, Japan
\end{abstract}

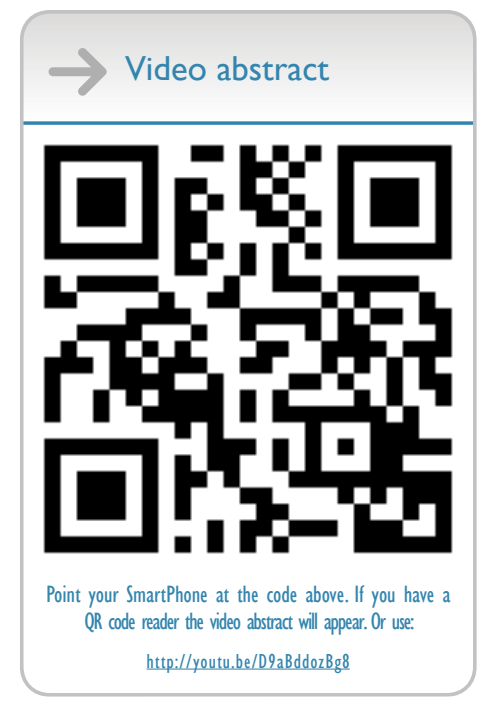

Correspondence: Junya Fukuoka

Department of Pathology, Nagasaki University Graduate School of Biomedical Sciences, I-7-I, Sakamoto, Nagasaki, 852-850I, Japan

$\mathrm{Tel}+81958197055$

Fax +8I 958197054

Email fukuokaj@nagasaki-u.ac.jp

Purpose: Pulmonary emphysema is the pathological prototype of chronic obstructive pulmonary disease and is also associated with other lung diseases. We considered that observation with different approaches may provide new insights for the pathogenesis of emphysema.

Patients and methods: We reviewed tissue blocks of the lungs of 25 cases with/without emphysema and applied a three-dimensional observation method to the blocks. Based on the three-dimensional characteristics of the alveolar structure, we considered one face of the alveolar polyhedron as a structural unit of alveoli and called it a framework unit (FU). We categorized FUs based on their morphological characteristics and counted their number to evaluate the destructive changes in alveoli. We also evaluated the number and the area of pores of Kohn in FUs. We performed linear regression analysis to estimate the effect of these data on pulmonary function tests.

Results: In multivariable regression analysis, a decrease in the number of FUs without an alveolar wall led to a significant decrease in the diffusing capacity of the lung for carbon monoxide (DLCO) and DLCO per unit alveolar volume, and an increase in the area of pores of Kohn had a significant effect on an increase in residual capacity.

Conclusion: A breakdown in the lung framework and an increase in pores of Kohn are associated with a decrease in DLCO and DLCO per unit alveolar volume with/without emphysema. Keywords: lung, pathology, COPD, pulmonary function, pathogenesis

\section{Introduction}

Pulmonary emphysema is characterized by a decrease in gas exchange area of the capillary bed due to destruction of alveoli and loss of lung tissue. Pulmonary emphysema is the pathological prototype of chronic obstructive pulmonary disease (COPD) and is also associated with other lung diseases. ${ }^{1-6}$ Because COPD is a heavy burden and the leading cause of death worldwide, many studies have focused on emphysema and attempted to clarify its pathogenesis and morphogenesis with molecular, pathological, and radiological methods. ${ }^{7-12}$

However, there are some uncertain mechanisms of COPD, including negative airflow limitations in emphysema and the effect of abnormal diffusing capacity in ex-smokers without emphysema. ${ }^{13,14}$ The exact pathogenesis of the effect of smoking related to emphysema is not fully understood. We consider that microscopic observation with different approaches may provide new insight on the understanding of the pathogenesis of emphysema. We hypothesize that there are microstructural changes in the early stage of emphysema. Various lung studies have been performed using observation by a scanning electronic microscope. ${ }^{15-17}$ In cases with emphysema, Nagai et al reported an increase in pores of Kohn, which are pathways for collateral ventilation between two adjacent alveoli. ${ }^{16,18,19}$ 
Recent advances in technology allows three-dimensional (3D) analysis using a confocal microscope or digital reconstruction of pathological images. ${ }^{20}$ Onozato et al studied lung adenocarcinoma with digitally reconstructed 3D imaging and found that floating micropapillary structures are connected to the base of papillae with a fibrovascular core. ${ }^{21} \mathrm{We}$ recently used a method for 3D observation of lung cancer ${ }^{22}$ and applied it in the present study to identify small morphological change in pulmonary emphysema.

\section{Patients and methods Setting and cases}

Patients who had undergone lobectomy from 2013 to 2014 at our institution and had multiple blocks for background lung parenchyma were reviewed sequentially. One formalin-fixed paraffin-embedded block of each case was selected from the area of histologically unremarkable lung parenchyma with the observation of hematoxylin and eosin slides (Figure 1A). All lung tissues were similarly inflated according to the Department of Pathology standard operating procedures manual, fixed with $10 \%$ formaldehyde, and embedded into paraffin blocks. Cases with little unremarkable area and/or unsuccessful inflation were not selected. Ten cases with and 15 cases without pathological emphysema were included. Pathological centriacinar emphysema in this study was confirmed by a pulmonary pathologist who was blinded to the clinical information. This study was approved by the Nagasaki University Hospital Clinical Research Ethic Committee (approval number: 15022342). The research protocol of this study was disclosed in the website of Clinical Research Center of Nagasaki University Hospital. The ethics committee does not require patient consent as any personal information that could identify the patient has been removed.

\section{Thick sections of the lung}

The selected blocks were warmed in a water bath at $50^{\circ} \mathrm{C}$ for 1 minute and cut in $300 \mu \mathrm{m}$ thick sections with a sliding microtome (Microm International $\mathrm{GmbH}$; Walldorf, Germany). The sections were placed into a thin plastic net insoluble for xylene. The sections were warmed in an incubator at $60^{\circ} \mathrm{C}$ for 30 minutes, deparaffinized with xylene (three baths, for 30 minutes), and hydrated through an ethanol gradient. The sections were stained with hematoxylin and eosin, dehydrated with stepwise baths of alcohol, and cleared with xylene. During the whole staining process, tissues were kept inside a plastic net. The sections were then removed from the net, placed on a glass slide, and mounted with a cover slip.

Five low-power fields ( $\times 40$ magnification, $2.4 \times 1.6 \mathrm{~mm}$ ) of unremarkable lung parenchyma for each thick section were randomly selected and images were obtained with a microscope (BX51; Olympus, Tokyo, Japan) and a digital camera (DP70; Olympus, Tokyo, Japan) (Figure 1B-F).

Through observation of thick sections, we found that the structure of alveoli was a polyhedral complex made up with edges of fibrous tissue and faces of alveolar membrane (Figure $1 \mathrm{~B}$ and $\mathrm{C}, \underline{\text { Videos } \mathrm{S} 1}-\underline{\mathrm{S} 2}$ ). We called the polygonal face of the polyhedron a framework unit (FU) (Figure 1D-F, Videos S1-S2), which is described in the "Results" section. We categorized FUs into four types based on their morphological characteristics: FUs without an alveolar wall (Figure 1D, asterisk), FUs with fragments of an alveolar wall (Figure 1E), FUs with an intact alveolar wall with pores (Figure 1D, a single dagger, and Figure 1F), and FUs with an intact alveolar wall without pores (Figure 1D, a double dagger). The numbers of each type of FUs were counted in a randomly selected low-power field of each slide.

For those FUs with an intact alveolar wall with pores and those without pores of Kohn, a series of multilevel images were obtained at $\times 100$ magnification. Those images were reconstructed to z-stack images with ImageJ (National Institutes of Health [NIH], Bethesda, MD, USA). Among FUs with an intact alveolar wall with pores, we counted the number of pores of Kohn, and measured the area of pores of Kohn in each FU. The area of each pore and summed area of all pores observed in one FU were evaluated as the percentage area of the FU. These percentage area data were transformed by natural logarithm to obtain a normal distribution.

If appropriate, measurement of FUs and pores of Kohn were performed two to five times in different low-power fields for each case. The mean values of the data were considered representative values of each case in statistical analysis.

\section{Clinical data}

We collected clinical data (age, sex, smoking history, the number of cigarettes smoked and dissected location of the lung), chest computed tomography (CT) images, and pulmonary function tests (vital capacity, forced vital capacity [FVC], forced expiratory volume in 1 second $\left[\mathrm{FEV}_{1}\right]$, functional residual capacity, residual volume [RV], total lung capacity, diffusing capacity of the lung for carbon monoxide [DLCO], DLCO per unit alveolar volume [DLCO/VA], and closing volume $[\mathrm{CV}]$ ) prior to lobectomy. For the purpose of statistical analysis, the dissected location of the lung was categorized into two groups, upper (including upper and middle lobes) and lower. The presence of emphysema was evaluated with chest CT imaging (CT emphysema) 

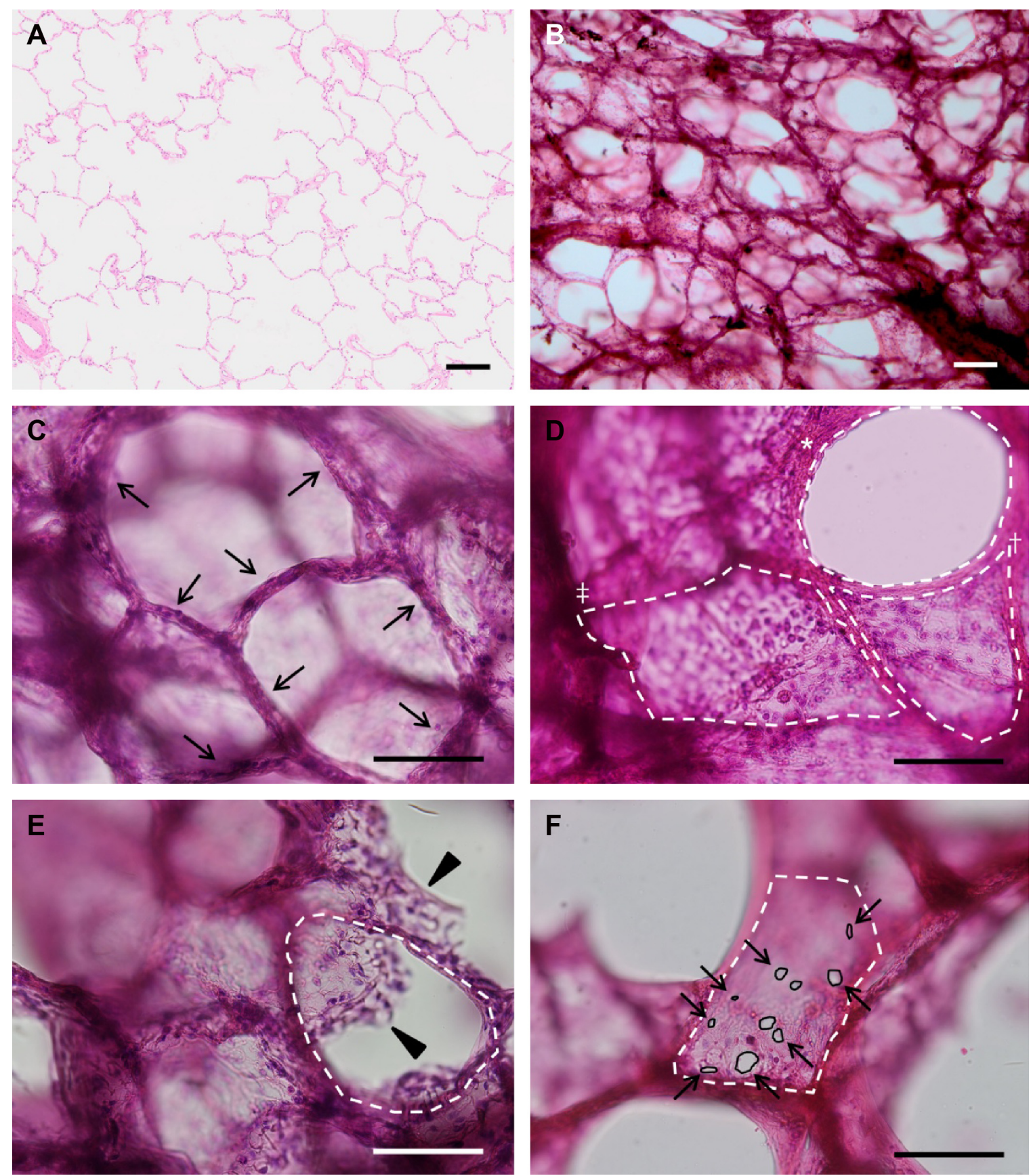

Figure I Images (H\&E) of the lung showing $4 \mu \mathrm{m}$ thick (A) and $300 \mu \mathrm{m}$ thick (B-F) sections at $\times 40$ magnification $(\mathbf{A}$ and $\mathbf{B})$ and $\times 100$ magnification $(\mathbf{C}-\mathbf{F})$.

Notes: The polyhedral complex of alveoli is composed of a framework (C, arrows) and an alveolar wall. We designated the face of the alveolar polyhedron as the FU (D-F, white dashed lines). We categorized FUs into four types based on their morphological characteristics: I) FUs without an alveolar wall (white dashed lines with an asterisk in D), 2) FUs with fragments of an alveolar wall (white dashed lines in E), 3) FUs with an intact alveolar wall with pores of Kohn (white dashed lines with a single dagger in $\mathbf{D}$ and white dashed lines in $\mathbf{F}$ ), and 4) FUs with an intact alveolar wall without pores of Kohn (white dashed lines with a double dagger in $\mathbf{D}$ ). The framework is thicker than the cut edges of the alveolar wall (E, arrowheads). The area of each pore and the sum of the area of all pores seen in one FU were evaluated by the percentage area of the FU (F, solid black line tracing and arrows). The black and white scale bars indicate $200 \mu \mathrm{m}$.

Abbreviations: FU, framework unit; H\&E, hematoxylin and eosin.

and was defined as $\geq 5 \%$ low attenuation area. ${ }^{3,14,23-25}$ The judgment of the presence of emphysema was confirmed by the consensus of the two pulmonary experts. All pulmonary function tests, except for $\mathrm{FEV}_{1} / \mathrm{FVC}$ and $\mathrm{CV}$, were expressed as $\%$ predicted; $\mathrm{FEV}_{1} / \mathrm{FVC}$ and $\mathrm{CV}$ were expressed as $\%$ observed and liters, respectively. Severity of airflow limitation was evaluated based on the COPD classification of the Global initiative for chronic Obstructive Lung Disease. ${ }^{2}$ For the purpose of statistical analysis, severity of airflow limitation was categorized into two groups, negative (no airflow limitation) and positive (mild, moderate, and severe airflow limitation). 


\section{Statistical analysis}

Variables were described with frequencies for categorical data and with median and interquartile range for quantitative data. Comparisons of clinical parameters, pulmonary function tests, and findings in thick sections between the groups that were negative or positive for pathological or CT emphysema was performed using the Fisher's exact test for categorical variables and the Wilcoxon's rank-sum test for quantitative variables. Linear regression analysis was used to estimate the effect of 3D findings in thick sections on pulmonary function tests. The variables with significant effect on pulmonary function tests in bivariable regression analysis were further assessed in multivariable analysis, including age, the number of cigarettes smoked, pathological emphysema, and CT emphysema as adjustment factors. The multivariable model with significant $P$-value of $F$ test and the smallest corrected Akaike information criterion was selected for each pulmonary function as the best model. We reported parameter estimates and 95\% confidential interval of variable in the models. JMP Pro 11.2.0 (SAS, Cary, NC,
USA) was used for statistical analysis. Two-tailed $P$-values $<0.05$ were considered significant.

\section{Results}

\section{Characteristics of the cases}

The mean of 4.3 low-power fields (107 in total) were available from 25 cases to observe and measure FUs and pores of Kohn. The numbers of the four types of FUs in total were 1,723 for FUs without an alveolar wall, 169 for FUs with fragments of an alveolar wall, 491 for FUs with an intact alveolar wall with pores, and 20 for FUs with an intact alveolar wall without pores. Pulmonary function tests were available in 23 of the 25 cases.

The characteristics of cases are shown in Table 1. According to COPD classification, 14 cases had no airflow limitation, while nine were considered abnormal; seven and two cases showed mild and moderate airflow limitation, respectively. No cases showed severe airflow limitation. When the negative and positive groups for emphysema were compared, pathological emphysema was associated with smokers, the higher number of cigarettes smoked, a lower

Table I Characteristics of the cases

\begin{tabular}{|c|c|c|c|c|c|c|}
\hline \multirow[t]{2}{*}{ Characteristic } & \multicolumn{2}{|c|}{ Pathological emphysema } & \multirow[t]{2}{*}{ P-value* } & \multicolumn{2}{|l|}{ CT emphysema } & \multirow[t]{2}{*}{$P$-value* } \\
\hline & Negative $n=\mid 5$ & Positive $n=10$ & & Negative $n=17$ & Positive $n=8$ & \\
\hline Age, years & $65.0(54.0,70.0)$ & $66.0(60.8,76.3)$ & 0.345 & $66.0(57.5,75.5)$ & $63.0(60.3,69.0)$ & 0.382 \\
\hline \multicolumn{7}{|l|}{ Sex } \\
\hline Male & 6 & 8 & 0.099 & 8 & 6 & 0.234 \\
\hline Female & 9 & 2 & & 9 & 2 & \\
\hline \multicolumn{7}{|l|}{ Smoking history } \\
\hline Nonsmoker & 14 & 5 & 0.023 & 13 & 6 & I \\
\hline Smoker & 1 & 5 & & 4 & 2 & \\
\hline $\begin{array}{l}\text { Number of cigarettes } \\
\text { smoked, pack-year }\end{array}$ & $0.0(0.0,0.0)$ & $15.0(0.0,50.6)$ & 0.022 & $0.0(0.0,15.0)$ & $0.0(0.0,27.0)$ & 0.938 \\
\hline \multicolumn{7}{|l|}{$\begin{array}{l}\text { smoked, pack-year } \\
\text { Dissected lobe }\end{array}$} \\
\hline Upper lobe & 11 & 8 & I & 17 & 8 & 0.129 \\
\hline Lower lobe & 4 & 2 & & 6 & 0 & \\
\hline Pulmonary function test & $n=13$ & $n=10$ & & $n=15$ & $n=8$ & \\
\hline VC, \% & II3.I (98.4, I23.6) & $105.3(101.1,124.5)$ & 0.620 & II $4.3(105.9,131.6)$ & $103.6(98.6,106.6)$ & 0.049 \\
\hline FVC, \% & III.I (96.4, I23.8) & $104.8(98.5,123.9)$ & 0.577 & III.6 (106.5, 132.8) & $102.3(94.2,105.9)$ & 0.039 \\
\hline $\mathrm{FEV}_{1}, \%$ & $108.2(91.7,132.9)$ & $93.1(81.3,137.3)$ & 0.292 & II $8.1(94.5,145.7)$ & $91.4(77.6,101.3)$ & 0.008 \\
\hline $\mathrm{FEV}_{\mathrm{I}} / \mathrm{FVC}, \%$ & $79.4(75.3,82.3)$ & $68.6(62.2,73.1)$ & 0.002 & $78.4(69.6,81.1)$ & $67.8(61.9,75.1)$ & 0.071 \\
\hline FRC, \% & II3.I (105.7, I36.8) & $98.2(82.9,117.0)$ & 0.063 & II3.I (105.6, I32.4) & $91.2(83.6,110.7)$ & 0.066 \\
\hline $\mathrm{RV}, \%$ & 105.7 (9I.I, 108.8) & $109.0(97.7,121.7)$ & 0.352 & $105.7(89.4,118.6)$ & $108.9(95.1,111.6)$ & 0.651 \\
\hline TLC, \% & $107.0(95.8,117.8)$ & $102.8(97.2,109.8)$ & 0.664 & $107.8(102.5,121.1)$ & $98.2(96.9,98.2)$ & 0.100 \\
\hline DLCO, \% & $90.6(80.7,97.8)$ & $68.9(60.4,80.7)$ & 0.006 & $90.5(76.6,94.3)$ & $65.8(59.8,77.0)$ & 0.008 \\
\hline DLCO/VA, \% & $93.2(81.9,102.4)$ & $69.3(53.3,77.8)$ & 0.002 & $84.9(75.7,97.1)$ & $64.0(48.4,81.0)$ & 0.011 \\
\hline $\mathrm{CV}, \mathrm{L}$ & $0.4 I(0.24,0.64)$ & $0.74(0.54,0.94)$ & 0.041 & $0.4 I(0.2 I, 0.7 I)$ & $0.67(0.55,0.79)$ & 0.081 \\
\hline \multicolumn{7}{|l|}{ Airflow limitation } \\
\hline Negative & 11 & 3 & 0.013 & 10 & 4 & 0.657 \\
\hline Positive & 2 & 7 & & 5 & 4 & \\
\hline
\end{tabular}

Notes: The quantitative data were expressed as median (IQR). *Fisher's exact test and Wilcoxon's rank-sum test were performed for categorical and quantitative variables, respectively.

Abbreviations: CT, computed tomography; CV, closing volume; DLCO, diffusing capacity of the lung for carbon monoxide; DLCO/VA, DLCO per unit alveolar volume; $\mathrm{FEV}_{1}$, forced expiratory volume in I second; FRC, functional residual volume; FVC, forced vital capacity; IQR, interquartile range; RV, residual volume; TLC, total lung capacity; VC, vital capacity. 
Table 2 Comparison of FUs and pores of Kohn between groups with and without emphysema

\begin{tabular}{|c|c|c|c|c|c|c|}
\hline \multirow[t]{2}{*}{ Variables } & \multicolumn{2}{|c|}{ Pathological emphysema } & \multirow[t]{2}{*}{$P$-value* } & \multicolumn{2}{|l|}{ CT emphysema } & \multirow[t]{2}{*}{$P$-value* } \\
\hline & Negative $n=15$ & Positive $n=10$ & & Negative $n=17$ & Positive $\mathbf{n}=\mathbf{8}$ & \\
\hline Number of FUs without an alveolar wall & $16.4(14.4,22.8)$ & $13.3(7.7,17.0)$ & 0.017 & $16.0(\mid 3.7,21.4)$ & $12.9(7.0,20.6)$ & 0.180 \\
\hline Number of FUs with fragments of an alveolar wall & $\mathrm{I} .0(0.5, \mathrm{I} .6)$ & $\mathrm{I} .3(0.3,3.7)$ & 0.760 & $\mathrm{I} .0(0.6, \mathrm{I} .8)$ & $0.4(0.0,4.0)$ & $0.4 \mid 4$ \\
\hline Number of FUs with an intact alveolar wall with pores & $5.2(3.6,5.8)$ & $4.1(3.1,5.3)$ & 0.317 & $4.3(3.8,5.8)$ & $4.3(2.4,5.6)$ & 0.540 \\
\hline Number of FUs with an intact alveolar wall without pores & $0.0(0.0,0.3)$ & $0.0(0.0,0.5)$ & 0.927 & $0.0(0.0,0.2)$ & $0.0(0.0,0.6)$ & 0.974 \\
\hline Number of pores in FUs & $5.0(3.7,7.5)$ & $8.0(4.6,10.4)$ & 0.088 & $5.7(4.2,7.9)$ & $6.4(3.4,12.0)$ & 0.600 \\
\hline Area percentage of one pore, not log-transformed, \% & $0.5(0.2,0.7)$ & $0.4(0.2,1.0)$ & 0.912 & $0.3(0.2,0.5)$ & $0.8(0.5,1.1)$ & 0.012 \\
\hline Area percentage of all pores, not log-transformed, \% & $1.6(0.9,3.2)$ & $2.2(0.9,7.6)$ & 0.471 & $1.2(0.9,2.5)$ & $3.9(2.1,9.7)$ & 0.014 \\
\hline
\end{tabular}

Notes: The quantitative data were expressed as median (IQR). *Wilcoxon's rank-sum test was performed.

Abbreviations: CT, computed tomography; FU, framework unit; IQR, interquartile range.

$\mathrm{FEV}_{1} / \mathrm{FVC}$, DLCO, and DLCO/VA, higher CV, and airflow limitation. On the other hand, CT emphysema was associated with a lower vital capacity, FVC, $\mathrm{FEV}_{1}$, functional residual capacity, DLCO, and DLCO/VA.

\section{Structure of alveoli}

Observation of thick sections showed that the structure of alveoli was a polyhedral complex made up with edges of fibrous tissue and faces of alveolar membrane (Figure 1B and $\mathrm{C}$, Video S1). The polyhedral complex of alveoli were arranged in a fractal manner throughout the lung (Figure 1B). In this study, one face of the alveolar polyhedron was considered as one FU (Figure 1D).

\section{Pulmonary function}

When compared between negative and positive groups for emphysema, the number of FUs without alveolar wall was significantly lower in cases positive for pathological emphysema ( $P=0.017$, Table 2), and the area percentage of one pore and all pores were significantly higher in the cases positive for CT emphysema ( $P=0.012$ and $P=0.014$, respectively, Table 2$)$.

In bivariable regression analysis, the number of FUs without an alveolar wall, the number of pores in FUs, the percentage area of one pore, and the percentage area of all pores had a significant effect on DLCO, DLCO/VA, and/or RV (bivariable, Tables 3-5). In multivariable regression analysis, the number of FUs without an alveolar wall had a positive effect on DLCO $(P=0.013$, multivariable, Table 3$)$ and DLCO/VA ( $P=0.001$, multivariable, Table 4$)$, and the percentage area of all pores had a positive effect on $\mathrm{RV}$ $(P=0.017$, multivariable, Table 5).

\section{Discussion}

In this study, we considered alveolar structure as a polyhedral complex according to 3D findings in thick sections. We hypothesized that the faces of the polyhedron are minimal microscopic units of the lung. We found that a smaller number of FUs without an alveolar wall and a larger area of pores of Kohn were significantly associated with emphysematous changes in pulmonary function tests (lower DLCO, lower DLCO/VA, and larger RV, Tables 3-5). Based on these findings, we hypothesized that lower diffusing capacity reflects lung tissue loss as a result of breakdown and merging of framework structure and alveoli (observed as a decrease in the number of FUs without an alveolar wall in this study). Another likely hypothesis is that an increase in pores of Kohn decreases the gas exchange area, capillary bed, and elastic recoil, which can increase physical vulnerability to maintain lung architecture.

Table 3 Bivariable and multivariable regression analysis on DLCO

\begin{tabular}{|c|c|c|c|c|}
\hline \multirow[t]{2}{*}{ Variables } & Bivariable & \multirow[t]{2}{*}{ P-value } & Multivariable & \multirow[t]{2}{*}{$P$-value } \\
\hline & Estimate $(95 \% \mathrm{CI})$ & & Estimate $(95 \% \mathrm{CI})$ & \\
\hline Number of FUs without an alveolar wall & $\mathrm{I} .6(0.4,2.8)$ & 0.010 & $1.3(0.3,2.4)$ & 0.013 \\
\hline Age, years & $-0.3(-1.1,0.6)$ & 0.494 & & \\
\hline Number of cigarettes smoked, pack-year & $0.1(-0.1,0.4)$ & 0.312 & $0.3(0.1,0.6)$ & 0.004 \\
\hline \multicolumn{5}{|l|}{ Pathological emphysema } \\
\hline Negative & Reference & - & Reference & - \\
\hline Positive & $-|8|.(-3 \mid .4,-4.8)$ & 0.010 & $-15.9(-29.4,-2.5)$ & 0.022 \\
\hline \multicolumn{5}{|l|}{ CT emphysema } \\
\hline Negative & Reference & - & Reference & - \\
\hline Positive & $-19.1(-32.9,-5.4)$ & 0.009 & $-4.6(-17.2,8.1)$ & 0.456 \\
\hline
\end{tabular}

Abbreviations: $\mathrm{Cl}$, confidential interval; $\mathrm{CT}$, computed tomography; DLCO, diffusing capacity of the lung for carbon monoxide; FU, framework unit. 
Table 4 Bivariable and multivariable regression analysis on DLCO/VA

\begin{tabular}{|c|c|c|c|c|}
\hline \multirow[t]{2}{*}{ Variables } & Bivariable & \multirow[t]{2}{*}{$P$-value } & \multirow{2}{*}{$\begin{array}{l}\text { Multivariable } \\
\text { Estimate }(95 \% \mathrm{Cl})\end{array}$} & \multirow[t]{2}{*}{$P$-value } \\
\hline & Estimate $(95 \% \mathrm{Cl})$ & & & \\
\hline Number of FUs without alveolar wall & $2.6(1.5,3.6)$ & $<0.001$ & $1.8(0.8,2.8)$ & 0.001 \\
\hline Number of pores in FUs & $-2.1(-4.0,-0.3)$ & 0.026 & & \\
\hline Percent area of all pores, log-transformed & $-10.0(-18.0,-2.0)$ & 0.016 & & \\
\hline Age, years & $-0.4(-1.4,0.5)$ & 0.366 & & \\
\hline Number of cigarettes smoked, pack-year & $-0.1(-0.5,0.2)$ & 0.385 & & \\
\hline \multicolumn{5}{|l|}{ Pathological emphysema } \\
\hline Negative & Reference & - & Reference & - \\
\hline Positive & $-26.1(-39.6,-12.6)$ & $<0.001$ & $-11.3(-23.7,1.0)$ & 0.070 \\
\hline \multicolumn{5}{|l|}{ CT emphysema } \\
\hline Negative & Reference & - & Reference & - \\
\hline Positive & $-22.5(-38.2,-6.8)$ & 0.007 & $-10.3(-22.1,1.5)$ & 0.083 \\
\hline
\end{tabular}

Abbreviations: $\mathrm{Cl}$, confidential interval; CT, computed tomography; DLCO/VA, diffusing capacity of the lung for carbon monoxide per unit alveolar volume; FU, framework unit.

According to our results and previous studies, ${ }^{16-19,26}$ morphological progression of pulmonary emphysema is proposed as follows: alveoli with a few tiny pores of Kohn in the normal state (Figure 2A- $\mathrm{A}^{\prime \prime}$ ) starts to show an increase in the number and size of pores of Kohn, leading vulnerability of the alveoli (Figure 2B-B"). The framework structure and alveoli merge and break down because of mechanical stress and/or inflammation, inducing traction of lung tissue (Figure $2 \mathrm{C}-\mathrm{C}^{\prime \prime}$ ). Finally, remodeling of acini results in enlarged air spaces of emphysema (Figure 2D-D").

Interestingly, breakdown of the lung framework and an increase in pores of Kohn showed significant associations with changes in pulmonary function, although these associations with pathological or radiological emphysema were not high (Table 2). Our finding that these small changes are associated with diffusing capacity stronger than pathological and radiological recognition of emphysema suggests that small changes in alveoli are an essential part of the reduction of diffusing capacity of emphysema or possibly other diseases.
Previous studies have attempted to describe the morphological and physiological features of the lungs. ${ }^{15-17,26-30} \mathrm{We}$ recently developed a histopathological approach to enable $3 \mathrm{D}$ observation of the lungs with thick sections. ${ }^{22}$ Using this method, we showed that string-like structures, the framework, and alveolar walls are assembled into a polyhedral complex of alveoli. Previous studies have already hypothesized that alveoli form a polyhedral structure, ${ }^{17,26,29}$ which we confirmed with our 3D observation technique. This is the first report to specifically describe the framework and alveolar wall as an edge and face. Because the framework was observed reticulating throughout the lung parenchyma (Figure 1B), and because the thickness of framework was different from that of simple cut edges of the alveolar wall (Figure 1E), we concluded that the framework is a string-like component, which is totally distinct from an alveolar wall. This framework may contribute to preserving the shape of pulmonary alveolar sacs and lobules together with surfactant proteins. This component may be difficult to identify with conventional histopathological techniques.

Table 5 Bivariable and multivariable regression analysis on RV

\begin{tabular}{|c|c|c|c|c|}
\hline \multirow[t]{2}{*}{ Variables } & Bivariable & \multirow[t]{2}{*}{$P$-value } & \multirow{2}{*}{$\frac{\text { Multivariable }}{\text { Estimate }(95 \% \mathrm{Cl})}$} & \multirow[t]{2}{*}{$P$-value } \\
\hline & Estimate $(95 \% \mathrm{Cl})$ & & & \\
\hline Number of pores in FUs & $1.9(0.2,3.6)$ & 0.034 & & \\
\hline Percent area of one pore, log-transformed & $26.4(0.7,52.1)$ & 0.045 & & \\
\hline Percent area of all pores, log-transformed & $8.0(0.3,15.7)$ & 0.041 & $7.9(1.5,14.3)$ & 0.017 \\
\hline Age, years & $0.02(-0.9,0.9)$ & 0.961 & & \\
\hline Number of cigarettes smoked, pack-year & $0.4(0.1,0.6)$ & 0.008 & $0.4(0.1,0.6)$ & 0.004 \\
\hline \multicolumn{5}{|l|}{ Pathological emphysema } \\
\hline Negative & Reference & - & & \\
\hline Positive & $7.5(-8.7,23.8)$ & 0.347 & & \\
\hline \multicolumn{5}{|l|}{ CT emphysema } \\
\hline Negative & Reference & - & & \\
\hline Positive & $-1.3(-18.6,16.0)$ & 0.878 & & \\
\hline
\end{tabular}

Abbreviations: $\mathrm{Cl}$, confidential interval; $\mathrm{CT}$, computed tomography; $\mathrm{FU}$, framework unit; RV, residual volume. 

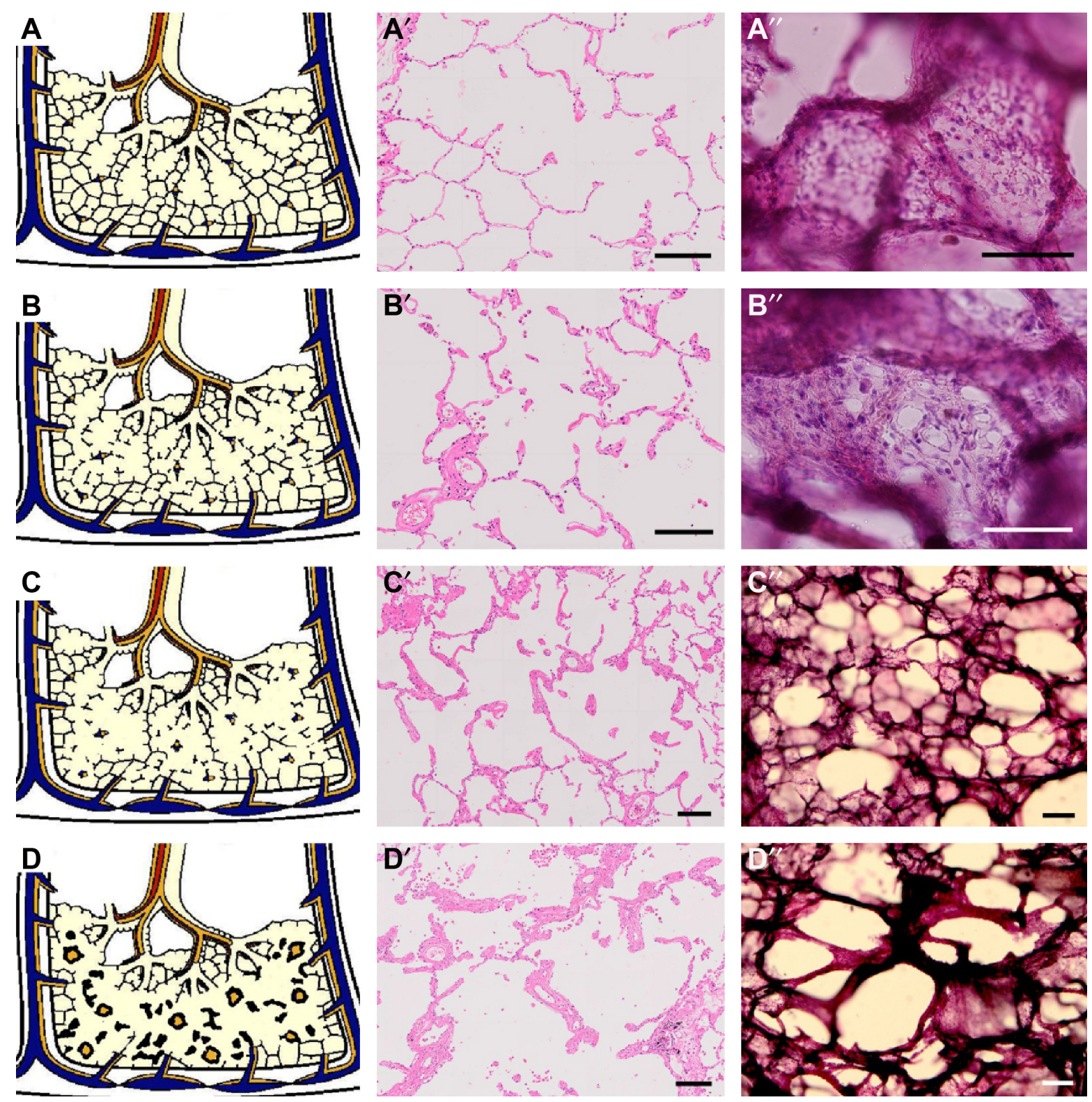

Figure 2 Schemas (A-D) and images of an ordinary H\&E slide $\left(A^{\prime}-D^{\prime}\right)$ and an H\&E thick section $\left(A^{\prime \prime}-D^{\prime \prime}\right)$ on possible progression of pulmonary emphysema.

Notes: Images $A^{\prime}$ and $B^{\prime}$ are at $\times 50$ magnification. Images $A^{\prime \prime}$ are $B^{\prime \prime}$ are at $\times 80$ magnification. Images $C^{\prime}, C^{\prime \prime}, D^{\prime}$, and $D^{\prime \prime}$ are at $\times 30$ magnification. According to our results, the morphological progression of pulmonary emphysema is proposed as follows: alveoli with a few tiny pores of Kohn in the normal state (A-A") starts to show an increase in the number and size of pores of Kohn, resulting in vulnerability of the alveoli (B-B"); the framework structure and alveoli merge and break down because of mechanical stress and/or inflammation, inducing traction of lung tissue (C-C"); and remodeling of acini resulting in enlarged air spaces of emphysema (D-D"). The pathological slide of images $A^{\prime}-D^{\prime}$ and the thick sections of image $A^{\prime \prime}-D^{\prime \prime}$ were processed from the same tissue block of an identical case. The black and white bars indicate $200 \mu m$. Abbreviation: H\&E, hematoxylin and eosin.

\section{Conclusion}

Based on the 3D characteristics of alveolar structure, breakdown of the lung framework and an increase in pores of Kohn are associated with a decrease in a diffusing capacity with/ without emphysema.

\section{Acknowledgments}

The authors thank Drs Harumi Ito at Fukui University, Lucian R Chirieac at Brigham and Women's Hospital, Eugene J Mark at Massachusetts General Hospital, and
Cesar A Moran at MD Anderson Cancer Center for critical discussions and advice. The schema of the lung that we edited and used in Figure 2 was designed by Dr Ryoko Egashira at Saga University. This study was partially supported by the Diffuse Lung Disease Research Group from the Ministry of Health, Labor, and Welfare, Japan.

\section{Author contributions}

$\mathrm{JF}$ is the guarantor of the content of the manuscript, including data collection and analysis. AY, SS, TT, and JF contributed 
to study design, data acquisition, data analysis, data interpretation, and drafting the manuscript. $\mathrm{MH}, \mathrm{YK}$, and $\mathrm{HY}$ contributed to interpretation of data and revision of the manuscript. TT, NY, and TN contributed to tissue acquisition and revision of the manuscript. All authors contributed toward data analysis, drafting and revising the paper and agree to be accountable for all aspects of the work.

\section{Disclosure}

The authors report no conflicts of interest in this work.

\section{References}

1. Hogg JC. Pathophysiology of airflow limitation in chronic obstructive pulmonary disease. Lancet. 2004;364(9435):709-721.

2. From the Global Strategy for the Diagnosis, Management and Prevention of COPD, Global Initiative for Chronic Obstructive Lung Disease (GOLD); 2016. Available from: http://goldcopd.org/. Accessed June 3, 2016.

3. Takahashi M, Fukuoka J, Nitta N, et al. Imaging of pulmonary emphysema: a pictorial review. Int J Chron Obstruct Pulmon Dis. 2008;3(2):193-204.

4. Hsia CC, Hyde DM, Ochs M, Weibel ER; Structure AEJTFoQAoL. An official research policy statement of the American Thoracic Society/ European Respiratory Society: standards for quantitative assessment of lung structure. Am J Respir Crit Care Med. 2010;181(4):394-418.

5. Margaritopoulos GA, Harari S, Caminati A, Antoniou KM. Smokingrelated idiopathic interstitial pneumonia: a review. Respirology. 2016; 21(1):57-64.

6. Hohberger LA, Schroeder DR, Bartholmai BJ, et al. Correlation of regional emphysema and lung cancer: a lung tissue research consortiumbased study. J Thorac Oncol. 2014;9(5):639-645.

7. Ochs M. Estimating structural alterations in animal models of lung emphysema. Is there a gold standard? Ann Anat. 2014;196(1):26-33.

8. Sharafkhaneh A, Hanania NA, Kim V. Pathogenesis of emphysema: from the bench to the bedside. Proc Am Thorac Soc. 2008;5(4):475-477.

9. Tuder RM, McGrath S, Neptune E. The pathobiological mechanisms of emphysema models: what do they have in common? Pulm Pharmacol Ther. 2003;16(2):67-78.

10. Mets OM, Buckens CF, Zanen P, et al. Identification of chronic obstructive pulmonary disease in lung cancer screening computed tomographic scans. JAMA. 2011;306(16):1775-1781.

11. Robbesom AA, Versteeg EM, Veerkamp JH, et al. Morphological quantification of emphysema in small human lung specimens: comparison of methods and relation with clinical data. Mod Pathol. 2003;16(1):1-7.

12. McDonough JE, Yuan R, Suzuki M, et al. Small-airway obstruction and emphysema in chronic obstructive pulmonary disease. $N$ Engl J Med. 2011;365(17):1567-1575.

13. Kirby M, Owrangi A, Svenningsen S, et al. On the role of abnormal $\mathrm{DL}(\mathrm{CO})$ in ex-smokers without airflow limitation: symptoms, exercise capacity and hyperpolarised helium-3 MRI. Thorax. 2013;68(8): $752-759$.

International Journal of COPD

\section{Publish your work in this journal}

The International Journal of COPD is an international, peer-reviewed journal of therapeutics and pharmacology focusing on concise rapid reporting of clinical studies and reviews in COPD. Special focus is given to the pathophysiological processes underlying the disease, intervention programs, patient focused education, and self management protocols.

Submit your manuscript here: http://www.dovepress.com/international-journal-of-chronic-obstructive-pulmonary-disease-journal
14. Lutchmedial SM, Creed WG, Moore AJ, Walsh RR, Gentchos GE, Kaminsky DA. How common is airflow limitation in patients with emphysema on CT scan of the chest? Chest. 2015;148(1):176-184.

15. Gehr P, Bachofen M, Weibel ER. The normal human lung: ultrastructure and morphometric estimation of diffusion capacity. Respir Physiol. 1978;32(2):121-140.

16. Nagai A, Inano H, Matsuba K, Thurlbeck WM. Scanning electronmicroscopic morphometry of emphysema in humans. Am J Respir Crit Care Med. 1994;150(5 Pt 1):1411-1415.

17. Weibel ER. What makes a good lung? Swiss Med Wkly. 2009; 139(27-28):375-386.

18. Van Allen CM, Lindskog GE, Richter HG. Gaseous interchange between adjacent lung lobules. Yale J Biol Med. 1930;2(4):297-300.

19. Terry PB, Traystman RJ, Newball HH, Batra G, Menkes HA. Collateral ventilation in man. N Engl J Med. 1978;298(1):10-15.

20. Germann JA, Davis LM. Three-dimensional tracking of a single fluorescent nanoparticle using four-focus excitation in a confocal microscope. Opt Express. 2014;22(5):5641-5650.

21. Onozato ML, Klepeis VE, Yagi Y, Mino-Kenudson M. A role of three-dimensional (3D) reconstruction in the classification of lung adenocarcinoma. Stud Health Technol Inform. 2012;179:250-256.

22. Yoshikawa A, Tsuruno K, Tanaka T, et al. Micropapillary structure of lung adenocarcinoma and spread through air space (STAS) in thicksection histology. Case Rep Clin Pathol. 2015;2(4):55-59.

23. Gould GA, MacNee W, McLean A, et al. CT measurements of lung density in life can quantitate distal airspace enlargement - an essential defining feature of human emphysema. Am Rev Respir Dis. 1988;137(2): 380-392.

24. Reilly J. Using computed tomographic scanning to advance understanding of chronic obstructive pulmonary disease. Proc Am Thorac Soc. 2006; 3(5):450-455.

25. Bhatt SP, Washko GR, Dransfield MT, Sieren JC, Newell JD Jr, Hoffman EA. Comparison of spirometric thresholds in diagnosing smoking-related airflow obstruction: authors' response. Thorax. 2014; 69(12):1147-1148.

26. Denny E, Schroter RC. Viscoelastic behavior of a lung alveolar duct model. J Biomech Eng. 2000;122(2):143-151.

27. Onuki T, Kanzaki M, Kikkawa T, et al. New findings on the three-dimensional anatomical relations between the bronchi and pulmonary blood vessels at the pulmonary hilum. Clin Anat. 2015;28(4): 506-511.

28. Hsia CC, Hyde DM, Ochs M, Weibel ER. How to measure lung structure - what for? On the "Standards for the quantitative assessment of lung structure". Respir Physiol Neurobiol. 2010;171(2):72-74.

29. Denny E, Schroter RC. The mechanical behavior of a mammalian lung alveolar duct model. J Biomech Eng. 1995;117(3):254-261.

30. Weibel ER, Bachofen H. How to stabilize the pulmonary alveoli: surfactant or fibers? Union Physiol Sci/Am Physiol Soc. 1987;2:72-75.
This journal is indexed on PubMed Central, MedLine and CAS. The manuscript management system is completely online and includes a very quick and fair peer-review system, which is all easy to use. Visit $\mathrm{http}: / / \mathrm{www}$.dovepress.com/testimonials.php to read real quotes from published authors. 